\title{
Effect of different fat replacers and drying methods on thermal behaviour, morphology and sensory attributes of reduced-fat coffee creamer
}

\author{
Simin Hedayatnia, ${ }^{\mathrm{a}, \mathrm{b}}$ Hamed Mirhosseini, ${ }^{\mathrm{a}, \mathrm{b}, *}$ Bahareh Tabatabaee Amid, ${ }^{\mathrm{a}, \mathrm{b}}$ Zaidul Islam Sarker, \\ Sanja Kostadinović Veličkovska, ${ }^{\mathrm{d}}$ Roselina Karim ${ }^{\mathrm{a}, \mathrm{b}}$ \\ a Department of Food Technology, Faculty of Food Science and Technology, Universiti Putra Malaysia, 43400 UPM Serdang, Selangor, Malaysia \\ ${ }^{\mathrm{b}}$ Department of Food Science, Faculty of Food Science and Technology, Universiti Putra Malaysia, 43400 UPM Serdang, Selangor, Malaysia \\ ${ }^{c}$ Faculty of Pharmacy, International Islamic University, Kuantan Campus, 25200 Kuantan, Pahang D/M, Malaysia \\ d Faculty of Agriculture, University "Goce Delčev", Krste Misirkov bb, 2000 Štip, Macedonia
}

\section{A R T I C L E I N F O}

Article history:

Received 19 April 2015

Received in revised form 23 April 2016

Accepted 2 May 2016

Available online xxx

Keywords:

Reduced-fat coffee creamer

Maltodextrin

Inulin

Stickiness

Fluidized-bed drying

\section{A B S T R A C T}

This study was conducted to investigate the effects of different fat replacers (i.e. inulin, $0,2.5,5$ and $7.5 \% \mathrm{w} / \mathrm{w}$; maltodextrin, $0,15,20$ and $25 \% \mathrm{w} / \mathrm{w}$ ) and agglomeration process on the characteristics of the reduced-fat coffee creamer. In the current work, the partial replacement of the hydrogenated fat with inulin and maltodextrin led to provide the reduced-fat creamer with desirable characteristics as compared to a commercial creamer. In this study, the creamer containing $25 \%$ maltodextrin and $7.5 \%$ inulin showed the highest glass transition temperature $\left(\mathrm{T}_{g}\right)$ and the lowest stickiness and moisture content among all formulated creamers. All instant-creamers from two-stage drying (spray drying followed by fluidized bed drying) had lower moisture content, bulk density, and stickiness as well as higher glass transition temperature $\left(\mathrm{T}_{\mathrm{g}}\right)$ than the regular-creamer from the one-stage spray drying only. This might confirm the significant positive impact of fluidized bed drying on the physicochemical properties and functional characteristics of the reduced fat creamer. The sensory analysis revealed that the partial replacement of fat with $25 \%$ maltodextrin and $7.5 \%$ inulin resulted in the most acceptable instant coffee creamer comparable with the commercial product.

(C) 2016 Published by Elsevier Ltd.

\section{Introduction}

Coffee is one of the most commonly consumed drinks in black or white form, depending on the preferred taste of the consumer. In general, a variety of milk and non-dairy products (creamers) are served for whitening purpose along with coffee (Kelly, Oldfield, \& O'Kennedy, 1999). The majority of coffee drinkers prefer to add creamer and/or whitener to the dark coffee. However, most of coffee creamers and whiteners are considered as unhealthy products because they contain a high amount of saturated fats and/or hydrogenated oil. The coffee creamer is produced in the liquid and powder forms. The powdered creamer is more preferred than the liquid creamer because of its longer shelf life, more availability and easier transportation. This is mainly because it contains lower moisture content and water activity $\left(\mathrm{a}_{\mathrm{w}}\right)$. In the technological point of view, the creamer powder should provide enough satisfaction in terms of instant properties, solubility, wettability, and dispersibility. It should dissolve rapidly without causing any coagulation or sedimentation in coffee (Kelly et al., 1999). The physicochemical properties of the creamer are mainly influenced by its composition and processing condition.

Spray drying technique is one of the most commonly applied techniques for manufacturing of creamer (Beeson \& Erickson, 2001). Spray drying is the transformation of feed from a liquid or slurry form to the powder form (Maa, Nguyen, Sit, \& Hsu, 1998). The for-

\footnotetext{
* Corresponding author. Department of Food Technology, Faculty of Food Science and Technology, Universiti Putra Malaysia, 43400 UPM Serdang, Selangor, Malaysia. Email address: hamedmi@upm.edu.my (H. Mirhosseini)
}

mation of amorphous sticky particles on the dryer chamber's wall is one of the main technological issues occurred in spray drying (Chiou $\&$ Langrish, 2007). The surface stickiness of particles would increase during spray drying at $150-180^{\circ} \mathrm{C}$, thus leading to stickiness of the particles to drying chamber walls and lowering the yield of production (Sudhagar, 2000). Such particle stickiness leads to loss of materials, thus increasing the manufacturing cost because of frequent switching off the dryer for cleaning (Bhandari \& Howes, 2005). On the other hand, spray-dried powders mainly have small particles $(<50 \mathrm{~mm})$ with poor handling and reconstitution properties (wettability, sinkability, dispersibility, and solubility); while it is more desired to have highly soluble powder, which does not form any lumps and aggregation after dissolving in water or milk. Such desired requirements can be achieved by applying agglomeration process (Turchiuli, Eloualia, El Mansouri, \& Dumoulin, 2005). Agglomeration refers to the formation of permanent large aggregates by sticking particulate materials and particles (Kage, Nishihara, Ishimatsu, Ogura, \& Matsuno, 2001).

In addition to agglomeration, the addition of proper and sufficient drying aid (such as skim milk powder and maltodextrin) to the premix formulation was recommended to overcome the stickiness and caking issues in powder products (Shrestha, Howes, Adhikari, $\&$ Bhandari, 2007). There are some cost- and technological limitations for using additives (e.g. fat replacers) in the powder products (Shrestha et al., 2007). Hence, the selection of a suitable fat replacer is highly encouraged to formulate a reduced-fat product with the desirable sensory attributes. Dietary fibers (such as inulin) are functional ingredients, which are commonly used in different food prod- 
ucts (Elleuch et al., 2011). Inulin is known as a prebiotic, which cannot be digested by human digestive enzymes (Pharmaceutiques, 1995). It has also many beneficial effects on the human health (Gibson, Probert, Van Loo, Rastall, \& Roberfroid, 2004). Inulin is classified to three groups based on the degree of polymerization (DP): native, shortchain and long-chain inulin (Glibowski \& Bukowska, 2011).

Maltodextrin is also one of the most commonly used drying aids in the food industry. It is a carbohydrate composed of D-glucose units and dextrose equivalent (DE) of $<20$ (Uthumporn, Zaidul, \& Karim, 2010). Maltodextrin can form the weak gel because of interactions between its helicoidal amylose and branched amylopectin molecules. Maltodextrin has been also used as a fat replacer, texture modifier and thickener. Maltodextrin plays a significant role in improving the glass transition temperature of the powder products, thus reducing the stickiness and caking issues. The characteristic of maltodextrin as a fat replacer is mainly because of its fat-like mouth-feel. This is presumably due to the formation of three-dimensional network especially when its gel has the irregularly shaped aggregates $(3-5 \mathrm{~mm}$ in diameter). Such gel with the large aggregate has very similar structure to fat crystals, presumably contributing fatlike behaviour (Chronakis, 1998). As stated by Shrestha et al. (2007), maltodextrin can protect sensitive food components against unfavorable environmental conditions.

The main objective of the present study was to investigate the effects of type and content of fat replacer (i.e. inulin and maltodextrin) and agglomeration on the particle morphology, physicochemical properties and sensory evaluation of the regular-and-instant reduced fat creamers. In this study, different regular coffee creamers were produced by a one-stage spray drying; while all instant coffee creamers were produced by a double-stage drying (i.e. spray drying followed by fluidized-bed drying). Physicochemical properties of all formulated creamers were compared with the control and commercial creamers (Table 1). To the best of our knowledge, there is a lack of fundamental research on the stickiness and other characteristics of the reduced fat regular and instant creamers.

\section{Material and methods}

\subsection{Chemicals and materials}

Maltodextrin $(\mathrm{DE}=10)$ was purchased from Roquette Freres Co. (Lestrem, France). Inulin (PubChem CID: 24763) was supplied by Cosucra Inc. (Fibruline X1, Warcoing, Warcoing, Belgium). Silicon dioxide (PubChem CID: 24261) was purchased from Sigma Aldrich (St. Louis, MO, USA). Di-potassium hydrogen phosphate (PubChem CID: 6096956) was obtained from Nacalai Tesque Co. (kyoto, Japan). In addition, soy lecithin (Kordel's Co. CA, USA), commercial skimmilk powder (Dutch lady Co, Kuala Lumpur, Malaysia), hydrogenated palm kernel oil (PKO), corn syrup and vanilla (Melaka, Malaysia) were purchased from different suppliers in Malaysia.

Table 1

The composition of commercial creamers applied for comparison purposes.

\begin{tabular}{lc}
\hline Composition $(\mathrm{g} / 100 \mathrm{~g})$ & Commercial creamer \\
\hline Fat & 34.0 \\
Carbohydrate & 61.0 \\
Protein & 2.0 \\
\hline
\end{tabular}

\subsection{Preparation of creamer emulsion}

Creamer emulsion was prepared according the following method: initially, the dispersed phase was prepared by mixing the hydrogenated palm kernel oil $(8 \% \mathrm{w} / \mathrm{w})$ and soy lecithin (emulsifier, $0.5 \%$ $\mathrm{w} / \mathrm{w})$ in a $100 \mathrm{~mL}$ beaker, covered with aluminum foil. Then, the mixture was heated at $80{ }^{\circ} \mathrm{C}$ and rotated at $100 \mathrm{rpm}$ for $20 \mathrm{~min}$ in the thermo controller water bath. The aqueous phase was prepared by gradually dispersing sodium caseinate $(2.5 \% \mathrm{w} / \mathrm{w})$, silicon dioxide (as an anti-caking agent, $1.0 \% \mathrm{w} / \mathrm{w})$, di-potassium hydrogen phosphate (as a stabilizer, $2.5 \% \mathrm{w} / \mathrm{w})$, skim-milk powder $(7 \% \mathrm{w} / \mathrm{w})$ and corn syrup solid $(15 \% \mathrm{w} / \mathrm{w})$ into $100 \mathrm{~mL}$ hot distilled water $\left(80 \pm 5^{\circ} \mathrm{C}\right)$. The solution was stirred with a magnetic stirrer at $100 \mathrm{rpm}$ for $5 \mathrm{~min}$ to achieve lump free solution. Subsequently, different concentrations of maltodextrin $(0 \%, 15 \%, 20 \%$ and $25 \%)$ and inulin $(0.0 \%, 2.5 \%, 5.0 \%$ and $7.5 \% \mathrm{w} / \mathrm{w}$ ) were gradually added to the aqueous phase to prepare different continuous phases. Then, it was continuously stirred at $100 \mathrm{rpm}$ for $5 \mathrm{~min}$ at $60 \pm 1{ }^{\circ} \mathrm{C}$. In the last stage, the dispersed phase was gradually added to the continuous phase. Then, the mixture was gently stirred for $10 \mathrm{~min}$ to prepare the coarse creamer emulsion. Finally, the coarse emulsion was homogenized by a high pressure homogenizer (APV, Crawley, UK) at 200 and $180 \mathrm{MPa}$ prior to drying. Finally, the homogenized creamer emulsion was dried by only spray dryer and/or spray dryer followed by fluidized bed dryer to prepare the regular and instant creamers, respectively. In this study, commercial creamer and control ( $0 \%$ inulin) were also considered for comparison purpose. It should be noted that fat plays a significant role in the sensory properties of coffee creamer. The coffee creamer with $100 \%$ fat replacement ( $0 \%$ fat) was also produced. Our preliminary analysis showed that the creamer with $0 \%$ fat did not provide any function like creamer after mixing with hot coffee.

\subsection{Spray drying}

The homogenized creamer emulsion was fed into a pilot scale mini spray dryer (BÜCHI model B-290, Flawil, Switzerland) (Fig. 1a). The sample was atomized with a rotary atomizer into the drying chamber with $1.2 \mathrm{~m}$ height and $0.87 \mathrm{~m}$ diameter. The recommended inlet and outlet temperatures for spray drying of thermo sensitive compounds are $180-220^{\circ} \mathrm{C}$ and $90-110^{\circ} \mathrm{C}$, respectively (Kim, Chen, \& Pearce, 2009). In the present study, the inlet and outlet air temperatures, pressure and feed flow rate were set at $180 \pm 5^{\circ} \mathrm{C}, 80 \pm 5{ }^{\circ} \mathrm{C}$, and $552 \mathrm{kPa}$ and $10(\mathrm{~mL} / \mathrm{min})$, respectively. A rubber toy was used to hint the drying chamber from outside as usual practice to collect more powder. This let to collect non-sticky powder from the drying chamber; while the very sticky powder cannot be taken by hinting drying chamber with a rubber toy. If the chamber is not hinted by the rubber toy, the production yield may not be high enough. After drying, the creamer powder was collected (Fig. 1a) and packed in the aluminum packing and stored in a desiccator prior to further analysis.

\subsection{Fluidized-bed drying}

In this study, a laboratory scale fluidized-bed dryer (AeromaticFielder AG, GEA Co, Copenhagen, Denmark) was used for agglomeration purpose. The processing conditions of fluidized-bed drying were as follow: $50{ }^{\circ} \mathrm{C}$ (inlet fluidizing air temperature), $5 \mathrm{~mL} / \mathrm{min}$ (solution feed rate), and $1.5 \mathrm{~m} / \mathrm{s}$ (atomizing air pressure) for $30 \mathrm{~min}$. For agglomeration purpose, the known amount $(150 \mathrm{~g})$ of the spray- 


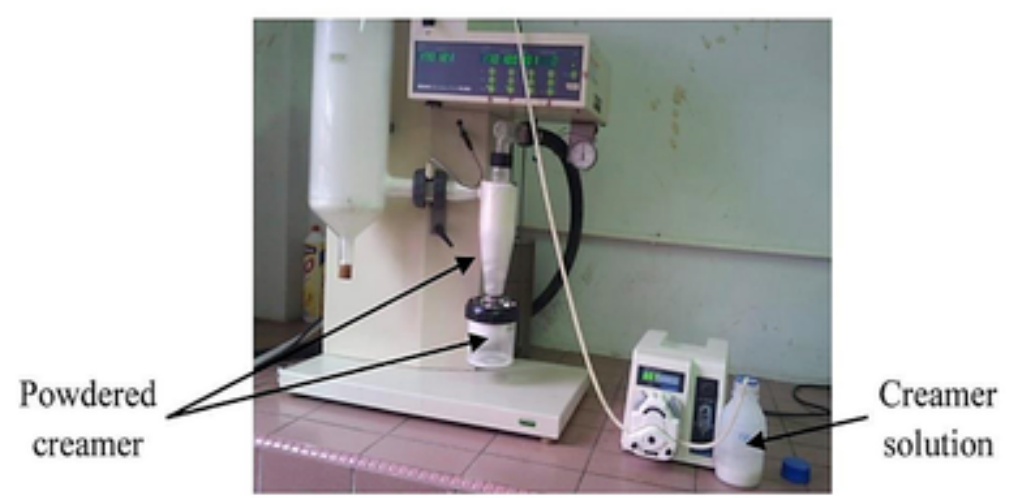

a)
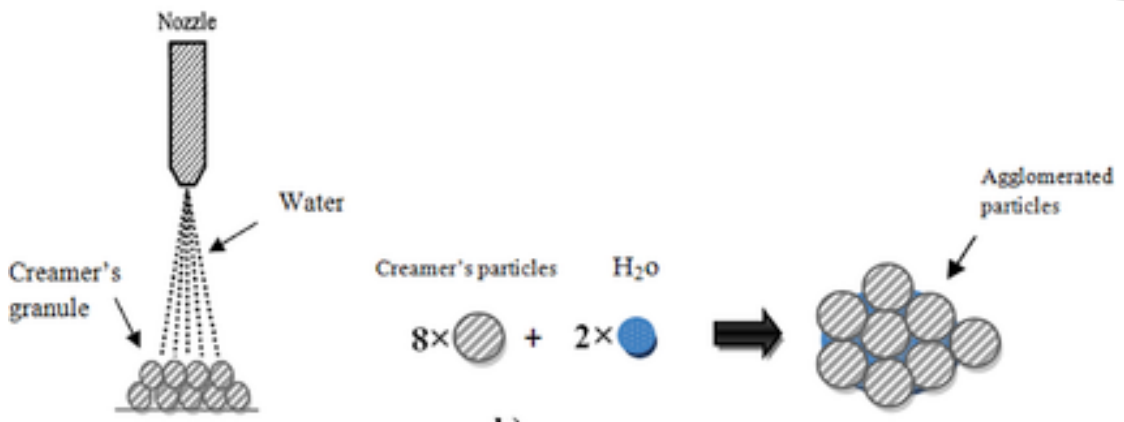

b)

Fig. 1. Our pilot scale spray dryer (a), and schematic figure of agglomeration process (b).

dried creamer was weighted and placed in the fluidized-bed drying chamber. Then, $30 \mathrm{~mL}$ aqueous solution containing lecithin $(2 \%$, w/ w) as a binder was sprayed through a nozzle, which was located at the top of the chamber. The solution droplets fell down on the creamer powders; while the filtrated hot air was flowed throughout the chamber from bottom of the chamber. This helped to reduce the moisture content and dustiness of particles (Fig. 1b). At the final drying stage, vanilla $(5 \% \mathrm{w} / \mathrm{w})$ was added to the instant powder because of the thermal sensitivity of its aromatic compounds. In order to maintain good fluidization, the air flow rate was increased as required during agglomeration process. Finally, the instant-creamer was dried at $35^{\circ} \mathrm{C}$ for 10 min to obtain the desirable moisture content. Instant creamer was collected, weighted, and packed in the aluminum bag and kept for further analysis.

\subsection{Analytical test}

\subsubsection{Analysis of moisture content}

The moisture content of regular-and-instant dried creamers was measured according to AOAC method 927.05 (2000). Moisture content was analyzed in triplicate for each sample and the result was expressed in wet basis.

\subsubsection{Determination of bulk density}

The bulk density of the reduced-fat creamers was measured according to WHO method (2012) with minor modification. In this method, creamer powder was passed through a sieve $(1.0 \mathrm{~mm})$ to obtain higher accuracy prior to the density analysis. Then, $\sim 5 \mathrm{~g}$ creamer was transferred into a $50 \mathrm{~mL}$ measuring glass cylinder (readable to $1 \mathrm{ml}$ ). The bulk density was calculated by dividing the mass of powder creamer to the apparent volume $\left(\mathrm{V}_{0}\right)$. The bulk density was mea- sured in triplicate for each sample. It was estimated based on the following equation:

Bulk density $\left(D_{B}\right)=m / V_{0}(g / m l)$

\subsubsection{Measurement of glass-transition temperature}

The glass-transition temperature $\left(\mathrm{T}_{g}\right)$ and thermal behavior of the regular-and-instant creamers were assessed by using a differential scanning calorimetry (DSC) (Mettler Toledo instruments DSC 823 Stockholm, Sweden). Before measurement, the samples were remained overnight in order to equilibrate the moisture content. For thermal behavior analysis, $\sim 6-8 \mathrm{mg}$ sample was placed in a preweighed Perkin-Elmer aluminum pan $(40 \mu \mathrm{L})$ without pins and manually sealed. Then, the sealed sample was heated from $27^{\circ} \mathrm{C}$ to $220^{\circ} \mathrm{C}$ at a scanning rate of $10^{\circ} \mathrm{C} / \mathrm{min}$ in DSC. The glass transition temperature was measured by $\mathrm{STAR}^{\mathrm{e}}$ thermal analysis program (version 6.0). The thermal behaviour of sample was determined in triplicate for each sample. An empty aluminum pan was used as a reference.

\subsubsection{Morphology analysis}

The surface morphology of the regular-and-instant creamers was monitored by a scanning electron microscope (SEM) (model LEO 1455VP with Oxford instrument and INCA software, London, UK). In this experiment, a small quantity of each sample was placed on an aluminum stub and then covered with a double-sided adhesive tape. Then, the sample was metallized by a standard $15 \mathrm{~nm}$ gold layer in a BAL-TEC sputter coater system (Model SCD 005, Balzers, Liechtenstein) in order to produce a great conductive surface prior to SEM analysis. 


\subsubsection{Solubility measurement}

The solubility was measured according to the method recommended by American Dairy Products Institute (ADPI, 1992) with minor modification. Approximately, $10 \mathrm{~g}$ creamer powder (dry basis) was poured in a beaker and blended with $100 \mathrm{ml}$ hot distilled water $\left(80 \pm 5^{\circ} \mathrm{C}\right)$ for $\sim 10 \mathrm{~min}$. Consequently, $50 \mathrm{ml}$ of the reconstituted creamer was transferred into a $50 \mathrm{ml}$ tube and centrifuged (IEC-Centra GP8, MA, USA) at $3000 \mathrm{rpm}(1089 \times \mathrm{g})$ for $5 \mathrm{~min}$. The sediment was re-suspended in hot distilled water $\left(80 \pm 5{ }^{\circ} \mathrm{C}\right)$ and re-centrifuged at $3000 \mathrm{rpm}$ for $5 \mathrm{~min}$. It was expressed in percentage by 100 - the volume $(\mathrm{ml})$ of the remained sediment after second centrifugation. The solubility was measured in triplicate for each sample.

\subsubsection{Measurement of average particle size}

Average particle size $(\mathrm{D}[4,3])$ was determined by measuring the surface-weighted mean (De Brouckere mean diameter, $\mathrm{D}_{4,3}$ ) of all formulated creamers. The experiment was carried out in triplicate for each sample. The experiments was performed by means of a particle size analyser with powder feeder unit (Model 2000 hydro S, Malvern Instrument, Worcestershire, UK) equipped with a Mastersizer software 2000 (Version 5.13).

Table 2

The matrix of the full factorial design.

\begin{tabular}{lll}
\hline Sample/run & Maltodextrin $(\%, w / w)$ & Inulin $(\%, w / w)$ \\
\hline 1 & 0 & 0.0 \\
2 & 0 & 2.5 \\
3 & 0 & 5.0 \\
4 & 0 & 7.5 \\
5 & 15 & 0.0 \\
6 & 15 & 2.5 \\
7 & 15 & 5.0 \\
8 & 15 & 7.5 \\
9 & 20 & 0.0 \\
10 & 20 & 2.5 \\
11 & 20 & 5.0 \\
12 & 20 & 7.5 \\
13 & 25 & 0.0 \\
14 & 25 & 2.5 \\
15 & 25 & 5.0 \\
16 & 25 & 7.5 \\
\hline
\end{tabular}

\subsubsection{Sensory evaluation}

For sensory attributes, the most desirable formulated creamer and a commercial creamer were chosen for sensory evaluation. The hedonic test was conducted by 30 trained panelists from different ages (22-43 years old) in Faculty of Food Science and Technology, Universiti Putra Malaysia (UPM). Initially, 100-ml reconstituted coffee was gently prepared by mixing $5 \mathrm{~g}$ instant coffee in $100-\mathrm{ml}$ hot water. Then the same amount $(3 \mathrm{~g})$ of the most desirable formulated creamer and commercial creamer were added to the same amount $(20 \mathrm{ml})$ of the reconstituted coffee. For each panel, two different coffee drinks $(20 \mathrm{ml})$ containing the most desirable creamer and commercial creamer were served in glass cups, which was coded with three random digit numbers. The panelists rated the taste, aroma, colour, and overall acceptability of both samples on a nine-point hedonic scale ranging from "dislike extremely, 1" to "like extremely, 9" (Hooda \& Jood, 2005).

\subsection{Statistical design and data analysis}

A full factorial design was considered to investigate the effect of different fat replacers as well as drying techniques (Table 2). The sample containing $0 \%$ maltodextrin and $0 \%$ inulin was considered as a control. The comparison among samples was carried out by running one way analysis of variance (ANOVA) and multiple pairwise comparison (Fisher test) at 95\% confident level (Table 3). Fisher test is based on the least significant difference (LSD) and it is one of the most recommended multiple comparisons. Fisher test can consider very minor to very major differences among samples. The data was subjected to the two way ANOVA to determine the significant $(p<0.05)$ or insignificant $(\mathrm{p}>0.05)$ effect of inulin or maltodextrin and their interaction (Table 4). Moreover, the effectiveness of agglomeration process was tested by running $t$-test between the regular and instant coffee creamers (before and after agglomeration, respectively). F-ratio was estimated to indicate the significant effect of inulin and maltodextrin on the physicochemical characteristics of creamer. The independent variable with a higher F-ratio has more significant effect than another independent variable with lower F-ratio. Minitab version 16.0 (Minitab Inc., State college, PA, USA) was used for data analysis.

Table 3

Two-way ANOVA for different analysis of regular and instant spray-dried creamers.

\begin{tabular}{|c|c|c|c|c|c|c|c|c|}
\hline \multirow[t]{3}{*}{ Creamer } & \multirow[t]{3}{*}{ Creamer characteristics } & \multicolumn{4}{|c|}{ Linear effect } & \multicolumn{2}{|c|}{ Interaction effect } & \multirow[t]{3}{*}{$\mathrm{R}^{2}$} \\
\hline & & \multicolumn{2}{|l|}{ Inulin } & \multicolumn{2}{|c|}{ Maltodextrin } & \multicolumn{2}{|c|}{ Inulin*Maltodextrin } & \\
\hline & & p-value & F-ratio & p-value & F-ratio & p-value & F-ratio & \\
\hline \multirow[t]{4}{*}{ Regular } & Moisture content & 0.000 & 43.4 & 0.000 & 967.9 & 0.604 & 0.8 & 0.985 \\
\hline & Bulk density & 0.000 & 34.9 & 0.000 & 780.9 & 0.557 & 0.9 & 0.983 \\
\hline & Thermal behaviour & 0.000 & 50.0 & 0.000 & 2193.0 & 0.007 & 4.0 & 0.995 \\
\hline & Solubility & 0.000 & 78.2 & 0.000 & 1728.2 & 0.009 & 3.9 & 0.994 \\
\hline \multirow[t]{4}{*}{ Instant } & Moisture content & 0.000 & 585.0 & 0.000 & 13899.0 & 0.000 & 12.0 & 0.998 \\
\hline & Bulk density & 0.000 & 156.0 & 0.000 & 2174.0 & 0.000 & 12.0 & 0.995 \\
\hline & Thermal behaviour & 0.000 & 251.0 & 0.000 & 6404.0 & 0.000 & 15.0 & 0.998 \\
\hline & Solubility & 0.000 & 73.0 & 0.000 & 2867.0 & 0.000 & 28.0 & 0.996 \\
\hline
\end{tabular}


Table 4

Student $t$-test of the regular-and-instant spray-dried creamers.

\begin{tabular}{|c|c|c|c|c|}
\hline Creamers & Mean & p-value & T-value & Parameters \\
\hline $\begin{array}{l}\text { RSRC } \\
\text { ISRC }\end{array}$ & $\begin{array}{l}5.24 \\
4.64\end{array}$ & 0.000 & 26.34 & Moisture content \\
\hline $\begin{array}{l}\text { RSRC } \\
\text { ISRC }\end{array}$ & $\begin{array}{l}0.61 \\
0.49\end{array}$ & 0.000 & 14.35 & Bulk density \\
\hline $\begin{array}{l}\text { RSRC } \\
\text { ISRC }\end{array}$ & $\begin{array}{l}40.92 \\
49.85\end{array}$ & 0.000 & -13.53 & Glass transition temperature \\
\hline $\begin{array}{l}\text { RSRC } \\
\text { ISRC }\end{array}$ & $\begin{array}{l}77.21 \\
81.29\end{array}$ & 0.000 & -7.49 & Solubility \\
\hline
\end{tabular}

RSRC: Regular spray-dried reduced-fat creamer, ISRC: instant spray-dried reduced-fat creamer.

\section{Results and discussion}

\subsection{Moisture content}

The removal of moisture can markedly improve the stability and shelf life of the powder material. Such moisture removal provides easier and cheaper handling, transportation and storage (http://ezproxy. upm.edu.my:2056/science/article/pii/S0260877413003543Bröckel,

Wahl, Kirsch, \& Feise, 2006). The moisture contents of different regular spray-dried creamers varied from $4.14 \%$ to $6.38 \%$ as compared to the control $(6.45 \%)$ and commercial creamer $(4.43 \%)$ (Fig. $2 a)$. The control sample ( $0 \%$ fat replacers) had the highest moisture content and stickiness among all samples. The creamer $\mathrm{M}$ containing $25 \%$ maltodextrin and $2.5 \%$ inulin and creamer $\mathrm{N}$ containing $25 \%$ maltodextrin and $5 \%$ inulin had almost similar moisture content to the commercial creamer (Fig. 2a). As stated by Kumar and Mishra (2004), the proper moisture content of the powder with the desirable characteristics is $4-5 \% \quad(\mathrm{w} / \mathrm{w})$. The

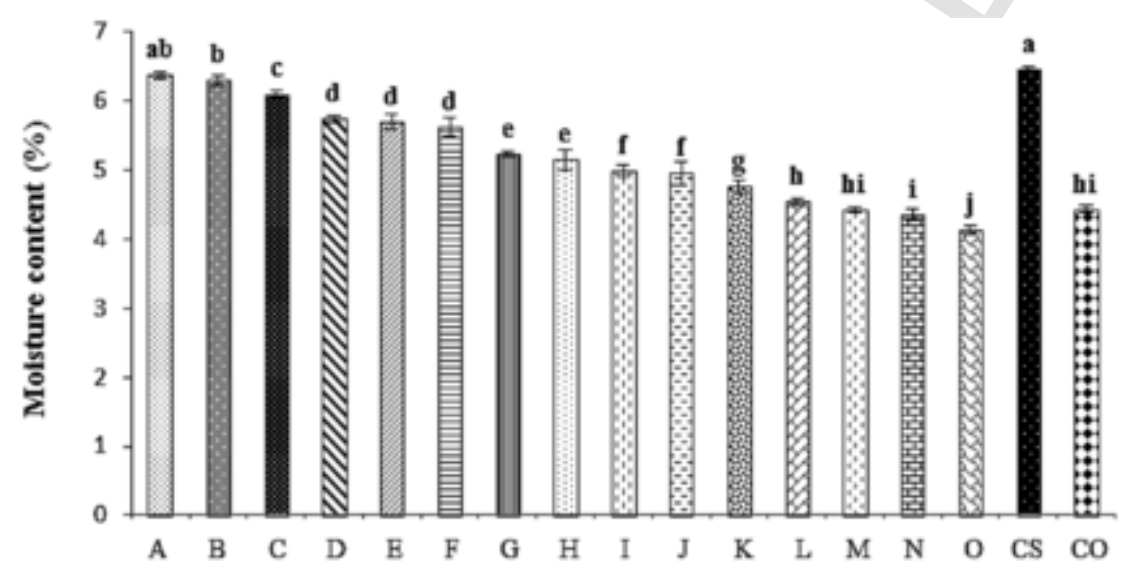

Regular spray-dried creamer formulations

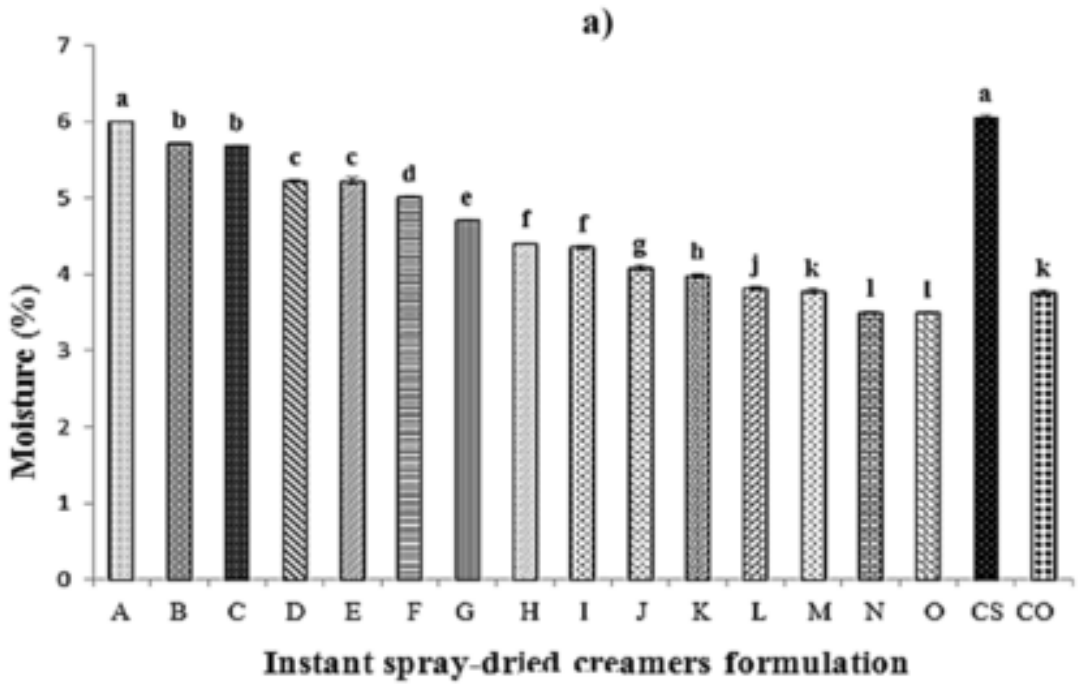

b)

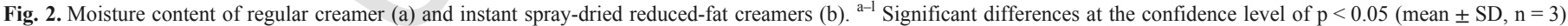

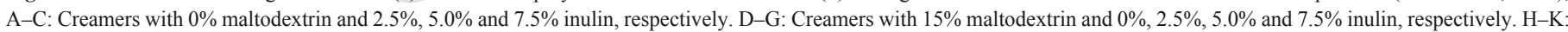

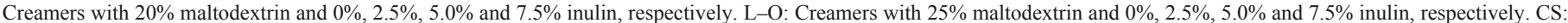
Control Creamer $(0 \%$ maltodextrin and $0 \%$ inulin; $\mathrm{CO}$ : commercial creamer. 
results showed that the addition of inulin and maltodextrin to the creamer formulation significantly affected the moisture content of the regular and instant creamers (Table 3 ).

The results indicated that the moisture content of the instant spraydried creamers varied from $3.49 \%$ to $6.0 \%$ in comparison with the control (6.05\%) and commercial creamer (3.77\%) (Fig. 2b). The regular-and-instant spray-dried creamers containing higher amounts of maltodextrin and inulin had lower moisture content than the creamers with lower content of fat replacers (Fig. 2a,b). This might be due to high water-binding capacity of maltodextrin and inulin. Such macromolecules can form junction zones and consequently enclose large amounts of water. This could be also due to the significant impact of high-level of feed solid, which resulted in more efficient reduction of the moisture content during evaporation and/or drying (Grabowski, Truong, \& Daubert, 2008). Similar finding was also reported by Mishra, Srivastava, Verma, Chauhan, and Rai (2009), wherein the moisture content of spray-dried Amla powder was significantly decreased from $5.6 \%$ to $3.8 \%$ by increasing maltodextrin content from $5 \%$ to $9 \%$ in its premix formulation.

Drying process is a critical food operation because it might be associated with unwanted changes in the texture, density, porosity, and sorption characteristics and overall quality of the dehydrated product (Drouzas, Tsami, \& Saravacos, 1999). Since the moisture content gradually decreased during drying, the characteristics of the dried products are highly influenced by the type and condition of drying techniques (Sundaram \& Durance, 2008). The moisture content of reduced-fat creamers was significantly influenced by the different drying techniques. The results showed that the application of agglomeration process through fluidized bed drying also significantly $(\mathrm{p}<0.05)$ influenced the moisture content of the creamer (Table 4). In fact, there was a significant difference between the moisture content of the regular creamer (before agglomeration) and instant creamer (after agglomeration). In this study, the instant-creamers had lower moisture content than the regular creamer with the similar formulation (Fig. 2a,b). This could be related to two-stage drying, which resulted in longer drying time (about $\sim 30 \mathrm{~min}$ ) in the fluidized-bed dryer than the one-stage spray drying only. This indicated that the application of spray drying followed by fluidized-bed drying resulted in the sample lower moisture content and consequently lower stickiness than the one-stage drying (spray drying). This may confirm the advantages of the agglomeration process via fluidized bed drying to modify the physical properties (i.e. flowability, density, dissolution, and dispersion characteristics) of powder, thereby reducing the tendency of powder to caking (Mukherjee \& Bhattacharya, 2006). Cruz, Passos, and Ferreira (2005) also reported that the moisture content of the whole milk and skim milk powders was decreased from $6-7 \%-3 \%$ and $4 \%$ by applying the fluidized bed drying.

\subsection{Bulk density}

The bulk density refers to the volume of the solid materials, and their pores (Dhanalakshmi, Ghosal, \& Bhattacharya, 2011). Fig. 3a,b shows the significant effects of the inulin and maltodextrin on the bulk density of regular-and-instant reduced-fat creamer. The bulk density of the regular spray-dried creamers ranged from 0.34 to $0.86(\mathrm{~g} /$ $\left.\mathrm{cm}^{3}\right)$ as compared to the control $\left(0.86 \mathrm{~g} / \mathrm{cm}^{3}\right)$ and commercial creamer $\left(0.42 \mathrm{~g} / \mathrm{cm}^{3}\right)$ (Fig. 3a). The control sample followed by the regular creamer A ( $0 \%$ maltodextrin and $2.5 \%$ inulin) had the highest bulk density among all regular spray-dried creamers; while the regular creamer O (25\% maltodextrin and $7.5 \%$ inulin) had the lowest bulk density among all regular spray-dried creamers (Fig. 3a). Similar trend was also observed for the instant creamers, wherein the in- stant creamer O containing the highest maltodextrin $(25 \%)$ and inulin $(7.5 \%)$ showed the minimum bulk density $\left(0.29 \mathrm{~g} / \mathrm{cm}^{3}\right)$ among all instant creamers; while the control creamer showed the maximum bulk density $\left(0.81 \mathrm{~g} / \mathrm{cm}^{3}\right)$ among all formulated instant spray-dried creamers (Fig. 3b). The current study revealed that the significant reduction in the bulk density was observed by increasing the proportion of maltodextrin and inulin in the creamer formulation. On the other hand, the reduction of bulk density might be due to the enlargement of particle size and/or reduction of moisture content. As also stated by Schuck, Jeantet, and Dolivet (2012), the bulk density and porosity of powder are highly affected by the particle size of powder and its moisture content, amount of air occluded in each particle, interstital air between particles and absolute density of powder.

The result also revealed the significant $(\mathrm{p}<0.05)$ effect of two different drying methods on the bulk density of the reduced-fat creamers (Table 4). This finding was also reported by Nep and Conway (2011). As stated by Nep and Conway (2011), drying technique and condition play a significant $(\mathrm{p}<0.05)$ role in altering the characteristics (i.e. porosity, bulk density and particle size) of the powder. The bulk density of the regular-and-instant creamers ranged from 0.29 to 0.86 (g/ $\mathrm{cm}^{3}$ ) depending on the drying method and stage (Fig. 3a,b). The application of fluidized-bed drying for agglomeration led to decrease the bulk density of the instant creamers. This might be explained by enlarging particle size, expanding particle porosity and decreasing moisture content of the creamer. In fact, the particles with lower moisture content are less sticky than the particles with high moisture content. This will result in more narrow interspaces among particles, thereby reducing bulk density (Goula \& Adamopoulos, 2005). Similar observation was also reported by Gong, Zhang, Mujumdar, and Sun (2007) for bayberry powder. According to Baruah, Das, Medhi, and Misra (2013), the higher porosity induced by agglomeration could result in lower bulk density based on the following equation ([1- (bulk density/granule density) $] \times 100)$. The reduction of the bulk density could result in the noticeable effect on the transportation cost (Aguilar \& Ziegler, 1994).

\subsection{Thermal behaviour}

Stickiness, unwanted agglomeration and caking issues are the main quality issues in the powder materials especially in spray-dried powders with the high sugar content. Stickiness and caking issue might be because of the high content of low molecular weight carbohydrates (i.e. glucose, fructose, and sucrose) in the powder formulation. Such quality issues are more obvious when the glass transition temperature $\left(T_{g}\right)$ of the powder is in the range of storage temperature. As also indicated by Bhandari and Howes (1999), the crystallization, agglomeration, and caking properties of the powder are highly affected by the glass transition temperature $\left(\mathrm{T}_{g}\right)$. The glass transition $\left(\mathrm{T}_{\mathrm{g}}\right)$ is normally defined as the phase, which amorphous particle transfers to the state of crystalline. $T_{g}$ is greatly affected by the thermal history of the material (Ren, Li, Wang, Özkan, \& Mao, 2010) and the presence of the residual water or other plasticizing substances.

In this study, DSC analysis was applied to determine the glass transition temperature $\left(\mathrm{T}_{g}\right)$ of the regular-and-instant creamers (Fig. 4a,b). It was evaluated from the onset point of the shift. In this study, the glass transition temperature $\left(\mathrm{T}_{\sigma}\right)$ of the regular spray-dried creamer varied from $\sim 31.54$ to $\sim 55.32{ }^{\circ} \mathrm{C}$, as compared to the control $\left(30.98{ }^{\circ} \mathrm{C}\right)$ and commercial creamers $\left(42.40^{\circ} \mathrm{C}\right)$ (Fig. $\left.4 \mathrm{a}\right)$. The results indicated that the type and content of fat replacers (i.e. inulin and maltodextrin) significantly $(\mathrm{p}<0.05)$ affected the glass transition temperature $\left(\mathrm{T}_{g}\right)$ of the regular spray-dried creamer. The control 

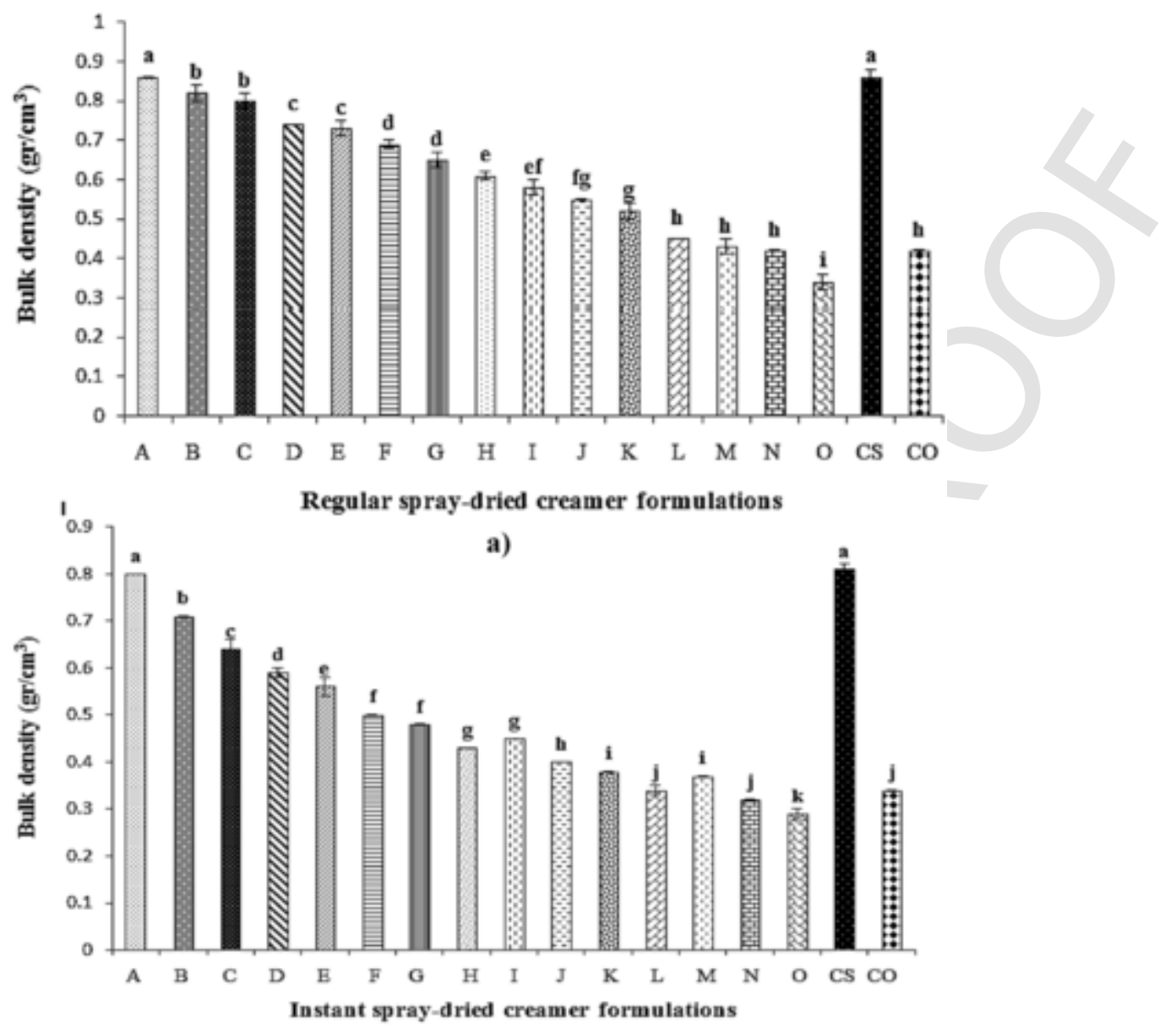

b)

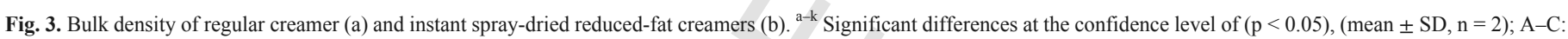

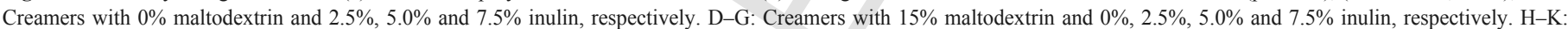

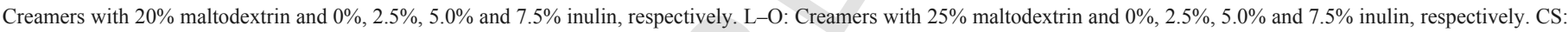
Control creamer $(0 \%$ maltodextrin and $0 \%$ inulin; $\mathrm{CO}$ : commercial creamer.

creamer and creamer $\mathrm{O}$ containing $25 \%$ maltodextrin and $7.5 \%$ inulin showed the lowest and highest glass transition temperature $\left(\mathrm{T}_{g}\right)$ among all regular spray-dried creamers, respectively. The highly sticky characteristics of the control could be because of its low glass transition temperature $\left(\mathrm{T}_{g}\right)$ and melting point as well as its high hygroscopic characteristics. Figs. 4 and 5 illustrated the significant effect of inulin and maltodextrin on the glass transition, stickiness and color of the regular spray-dried creamers. As reported by Shrestha et al. (2007), the glass transition temperature of powdered orange juice was markedly increased from $66^{\circ} \mathrm{C}$ to $97^{\circ} \mathrm{C}$ by increasing the maltodextrin content from $50 \%$ to $75 \%$. In addition, the commercial creamer exhibited slightly low $\left(\mathrm{T}_{g}\right)$ temperature, although it had low moisture content (Fig. 4a). Fig. 6 showed an endothermic shift of the glass transition temperature $\left(\mathrm{T}_{g}\right)$ of the regular spray-dried creamers, wherein the glass transition $\left(\mathrm{T}_{g}\right)$ was slightly increased by increasing the inulin content in the creamer formulation. The thermal behaviour of the formulated reduced fat creamer might be related to fatty acid composition of the applied PKO. The main fatty acid compositions of PKO were as follow: lauric $\mathrm{C} 12(44.1 \pm 2.3 \%)$, myristic $\mathrm{C} 14$ $(12.4 \pm 1.8 \%)$, palmitic C16 $(7.8 \pm 1.4 \%)$, capric C10 $(2.4 \pm 0.3 \%)$, oleic $(1.4 \pm 0.3 \%)$, elaidic $(2.6 \pm 0.5 \%)$, caprylic C8 $(3.6 \pm 0.7 \%)$, stearic $\mathrm{C} 18(17.9 \pm 0.8 \%)$ and other fatty acids $(10.1-10.6 \%)$.
The results showed that the glass transition temperature $\left(\mathrm{T}_{g}\right)$ of the instant spray-dried creamers varied from $\sim 34.73{ }^{\circ} \mathrm{C}$ to $\sim 68.48{ }^{\circ} \mathrm{C}$ as compared to the commercial creamer $\left(57.77^{\circ} \mathrm{C}\right)$ and control $\left(32.92{ }^{\circ} \mathrm{C}\right)$ (Fig. 4b). The current study revealed that the creamers containing higher inulin and maltodextrin contents had higher glass transition temperature $\left(\mathrm{T}_{g}\right)$ and lower stickiness than other formulated-creamers. In fact, the glass transition temperature $\left(\mathrm{T}_{g}\right)$ of all formulated creamers was increased by addition of higher amount of maltodextrin to the creamer formulation. This might be because of the large molecular weight and high glass transition temperature $\left(\mathrm{T}_{\mathrm{g}}\right.$, $\sim 139.7^{\circ} \mathrm{C}$ ) of maltodextrin (Chegini \& Ghobadian, 2005). The same trend was observed by increasing inulin content in the creamer formulation. This could be explained by the fact that the dietary fibers such as inulin have high water binding capacity and proper gel forming properties (Soukoulis, Lebesi, \& Tzia, 2009). This might be interpreted by the fact that the moisture content of the creamer was decreased by increasing its total solids.

The glass transition temperature $\left(\mathrm{T}_{g}\right)$ of the reduced-fat creamers was also significantly influenced by the drying methods (Fig. 4a,b). In the present study, the instant-creamers had significant $(p<0.05)$ higher glass transition temperature $\left(\mathrm{T}_{\mathrm{g}}\right)$ than the regular-creamer. This might confirm that the glass transition temperature of the reduced fat creamer was improved by agglomeration. This could be due 


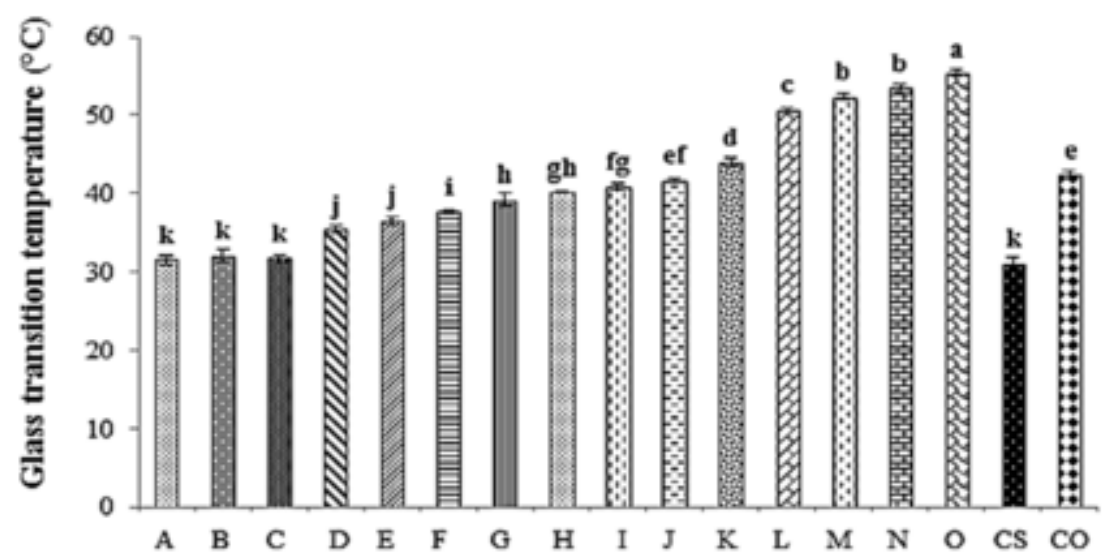

1 Regular spray-dried creamer formulations

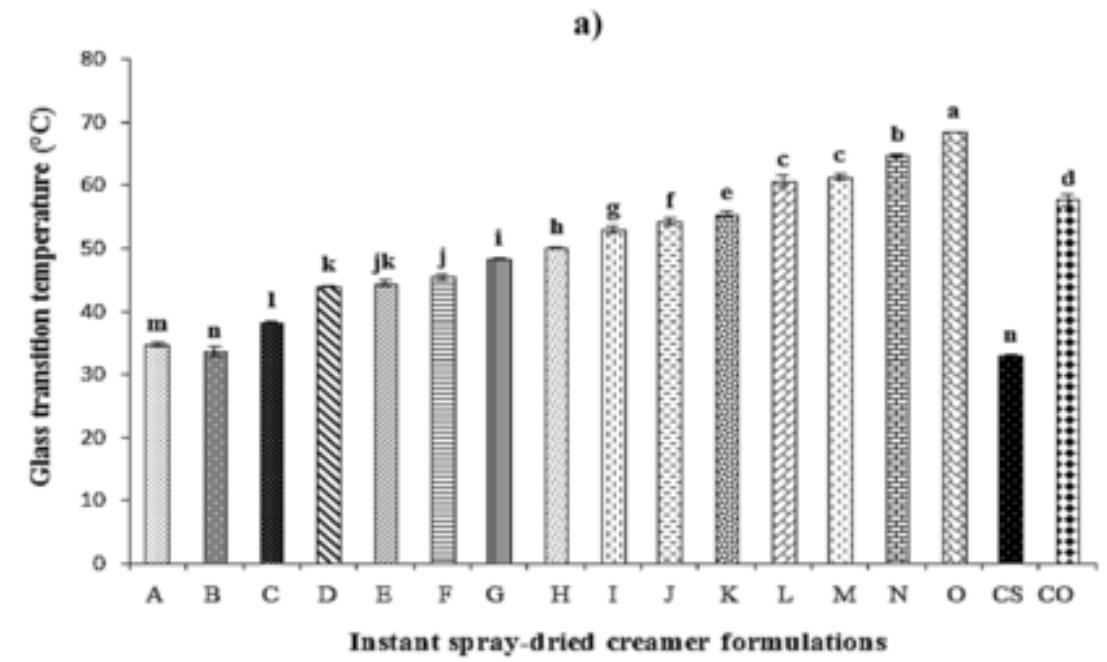

b)

Fig. 4. Glass transition temperature of regular creamer (a) and instant spray-dried reduced-fat creamers (b). ${ }^{a-k}$ Significant differences at the confidence level of ( $p<0.05$ ), $($ mean $\pm \mathrm{SD}, \mathrm{n}=2$ ); A-C: Creamers with $0 \%$ maltodextrin and $2.5 \%, 5.0 \%$ and $7.5 \%$ inulin, respectively. D-G: Creamers with $15 \%$ maltodextrin and $0 \%, 2.5 \%, 5.0 \%$ and $7.5 \%$ inulin, respectively. H-K: Creamers with $20 \%$ maltodextrin and $0 \%, 2.5 \%, 5.0 \%$ and $7.5 \%$ inulin, respectively. L-O: Creamers with $25 \%$ maltodextrin and $0 \%, 2.5 \%, 5.0 \%$ and $7.5 \%$ inulin, respectively. CS: Control creamer $(0 \%$ maltodextrin and $0 \%$ inulin; $\mathrm{CO}$ : commercial creamer.

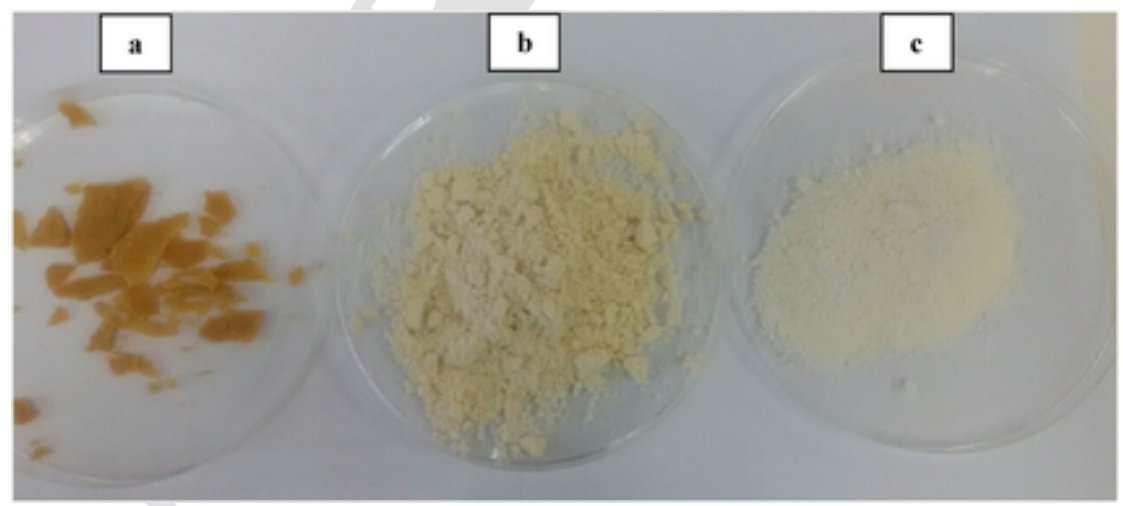

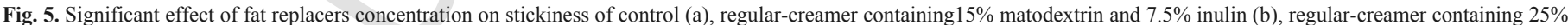
matodextrin and $7.5 \%$ inulin (c).

to the reduction of the available moisture content through agglomeration via fluidized-bed drying. Similar observation was also reported by Ren et al. (2010) for the micronized cassava starch. According to
Johari, Hallbrucker, and Mayer (1987), pure water is one of the strongest plasticizer and it has very low glass transition temperature $\left(-135^{\circ} \mathrm{C}\right)$; therefore the reduction of such pure water could decrease 


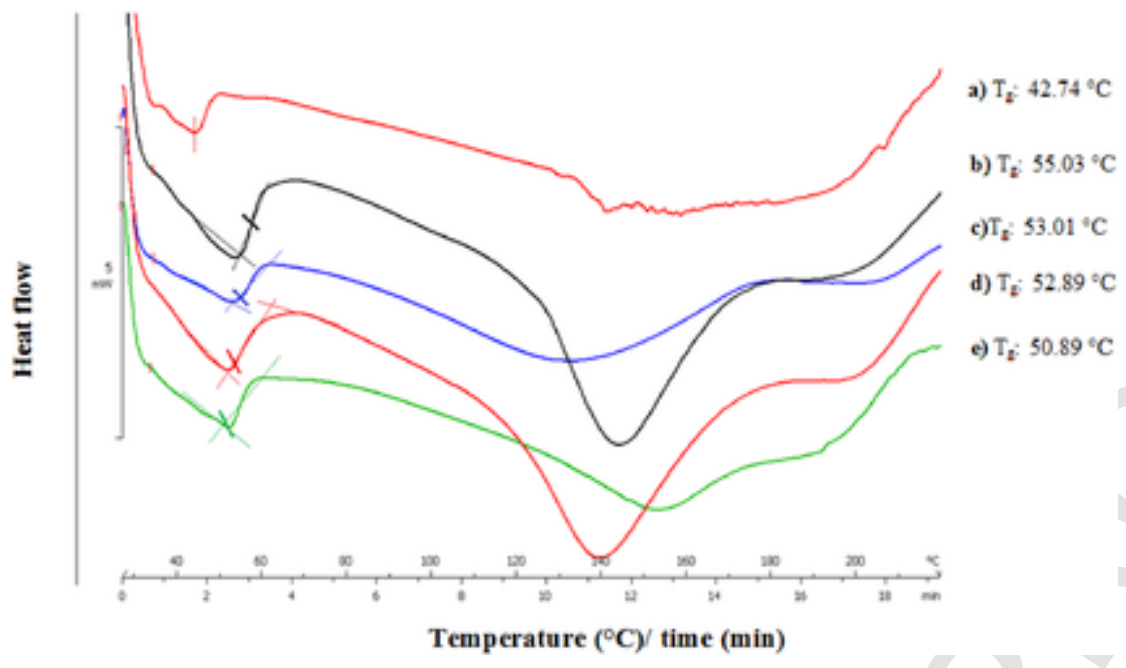

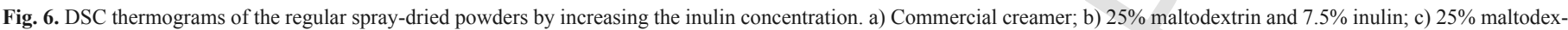
trin and $5 \%$ inulin; d) $25 \%$ maltodextrin and $2.5 \%$ inulin; e) $25 \%$ maltodextrin and $0 \%$ inulin.

the glass transition temperature $\left(\mathrm{T}_{\mathrm{g}}\right)$ of the powder. As also reported by Shrestha et al. (2007), the glass transition temperature $\left(\mathrm{T}_{\mathrm{g}}\right)$ of skim milk powder decreased from $47.7^{\circ} \mathrm{C}$ to $-3.5^{\circ} \mathrm{C}$ by increasing the moisture content from $0.0 \%$ to $5.6 \%$. They found that the skim milk powder with higher moisture content had lower glass transition temperature.
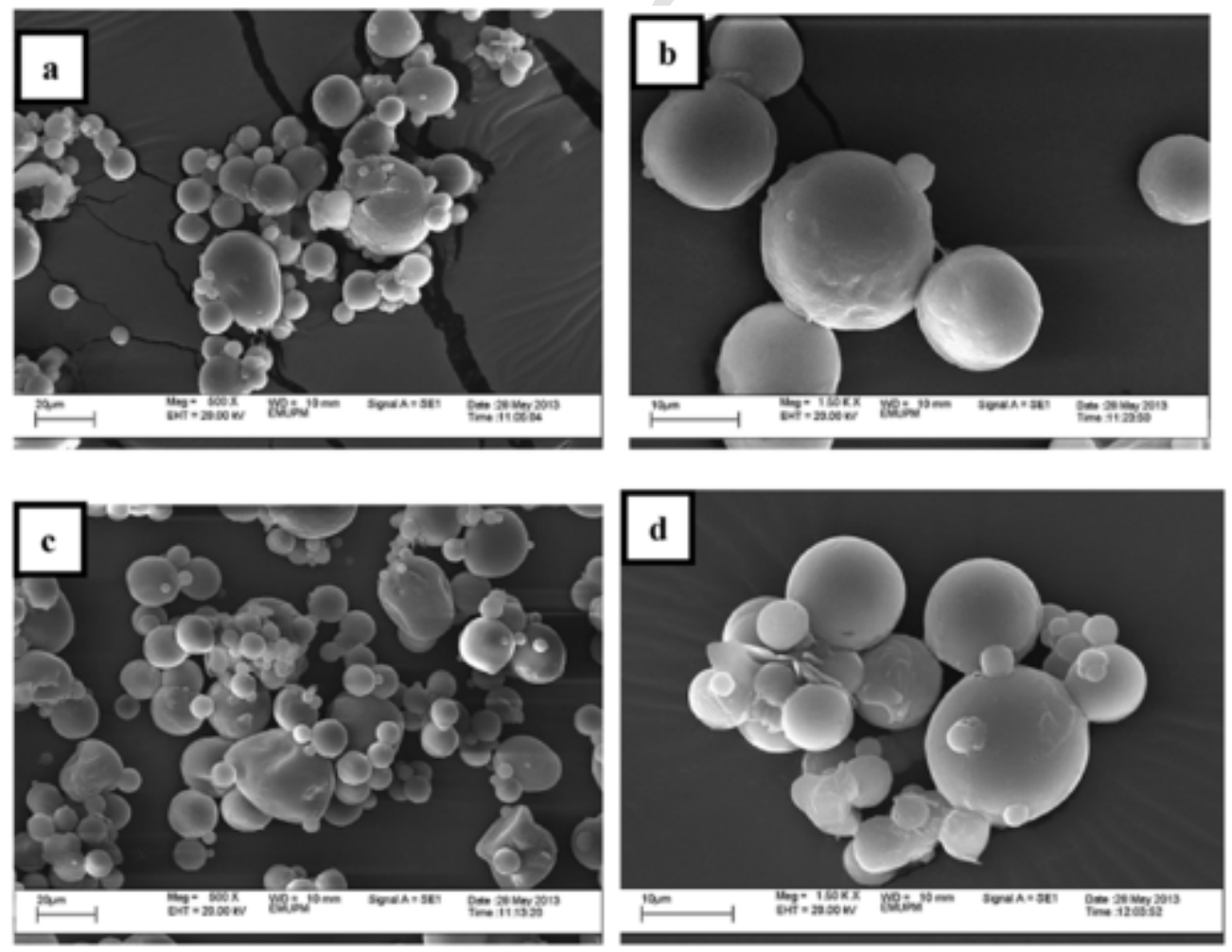

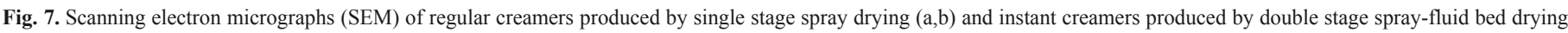
$(\mathrm{c}, \mathrm{d})$. 
spherical shape particles with smooth surfaces; while the application of lower inlet temperature $\left(142{ }^{\circ} \mathrm{C}\right)$ resulted in different particle shapes with the rough surface. Caparino et al. (2012) also reported almost similar microstructure for spray-dried mango powder. This indicated that the microstructure of powder is highly influenced by the type and condition of drying process.

SEM analysis showed different microstructure and morphology of the regular-and-instant reduced-fat creamers (Fig. 7a-d). The current study revealed that the application of fluid-bed drying resulted in larger particles and this is because of the linkage of small particles with other particles. The instant creamers (Fig. 7c,d) showed larger spherical particles than the regular creamers with the similar formulations (Fig. 7a,b). This is because the agglomeration induced by fluidized-bed drying leads to increase the interstitial air volume and porosity among particles, thus reducing the amount of fine particles. This could be also due to the fact that the particles of the instant powder have wider specific surface area than that of the regular powder (Mounir \& Allaf, 2008).

\subsection{Solubility}

Fig. 8(a,b) shows the effects of inulin and maltodextrin on the solubility of regular-and-instant reduced-fat creamers. As shown in Fig.
$8 \mathrm{a}$, different regular reduced fat creamers showed different solubility ranging from $60.38 \%$ to $93.13 \%$ as compared to the control $(57.13 \%)$ and commercial creamer $(93.09 \%)$. The control showed the lowest solubility among all formulated creamers; while the creamer containing high amount of maltodextrin (25\%) and inulin (7.5\%) showed very high solubility (93.13\%) as compared to other formulated creamers. The result was in accordance with the finding reported by Goula and Adamopoulos (2008). The solubility of the spray-dried tomato pulp was considerably improved by addition of maltodextrin to the premix. In the present study, the solubility of the regular-and-instant creamers was increased by addition of higher amount of inulin and maltodextrin to the creamer formulation (Fig. 8a,b). This could be related to the lower moisture content of the creamer containing higher contents of inulin and maltodextrin (Goula \& Adamopoulos, 2005). It should be noted that the addition of maltodextrin to the creamer formulation could improve its particle crust, thus enhancing its solubility (Desai \& Park, 2004) (see Fig. 9).

The drying process also significantly $(\mathrm{p}<0.05)$ affected the solubility of the reduced-fat creamers (Fig. 8a,b). Nep and Conway (2011) reported that the solubility of grewia gum was also significantly $(\mathrm{p}<0.05)$ affected by drying process. They found that the application of different drying techniques resulted in the gums with different molecular weights and different solubility. The results showed

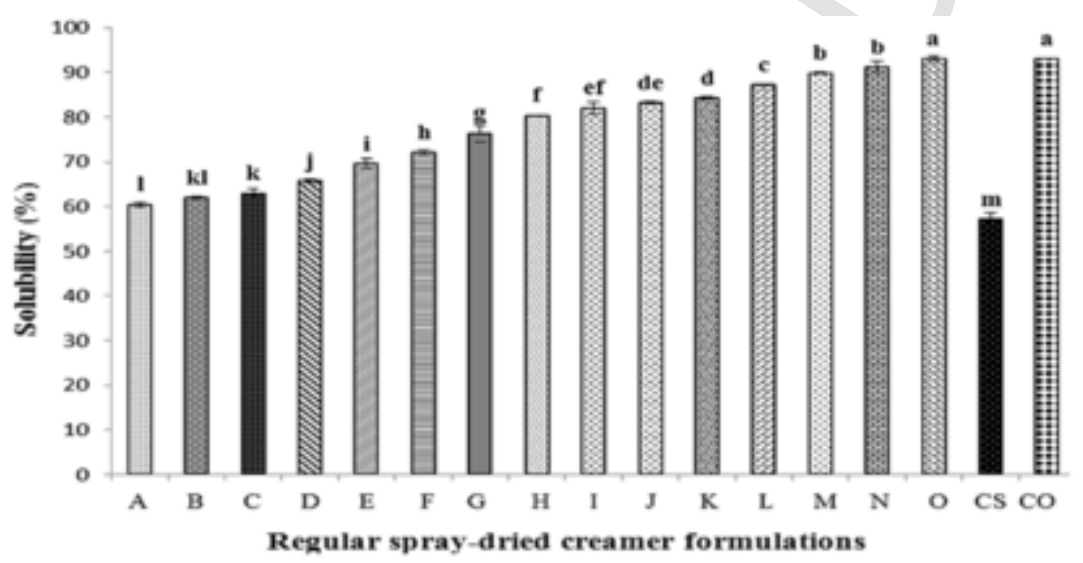

a)

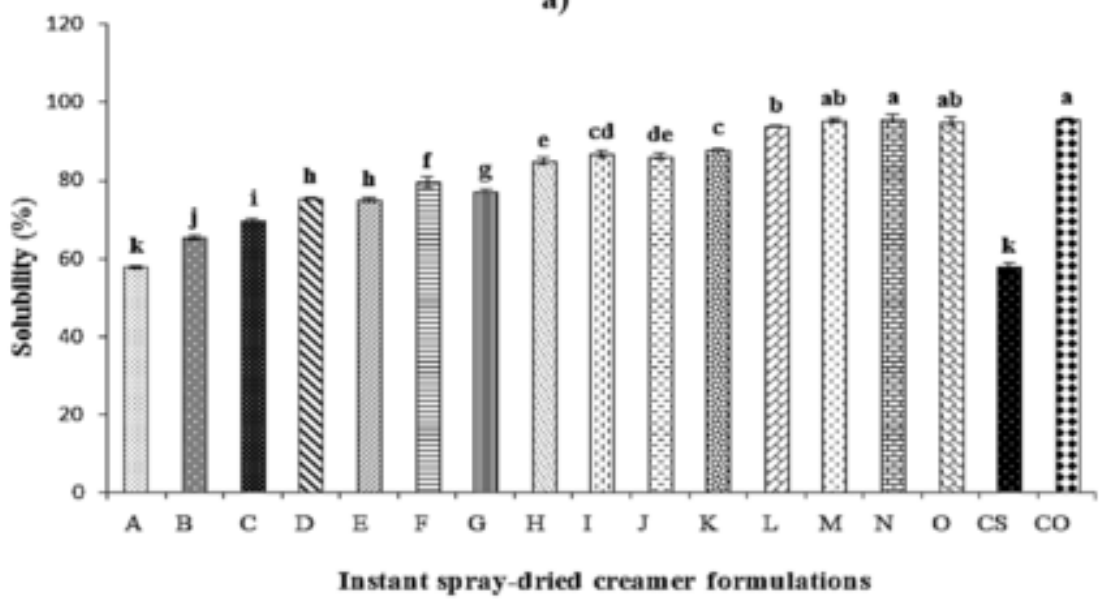

b)

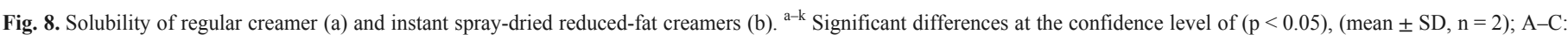

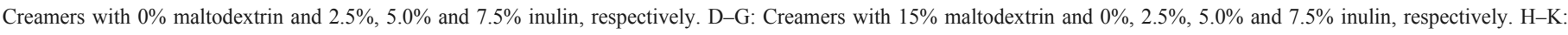

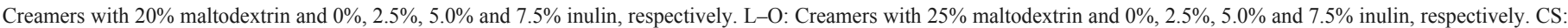
Control sample $(0 \%$ maltodextrin and $0 \%$ inulin; $\mathrm{CO}$ : commercial creamer. 


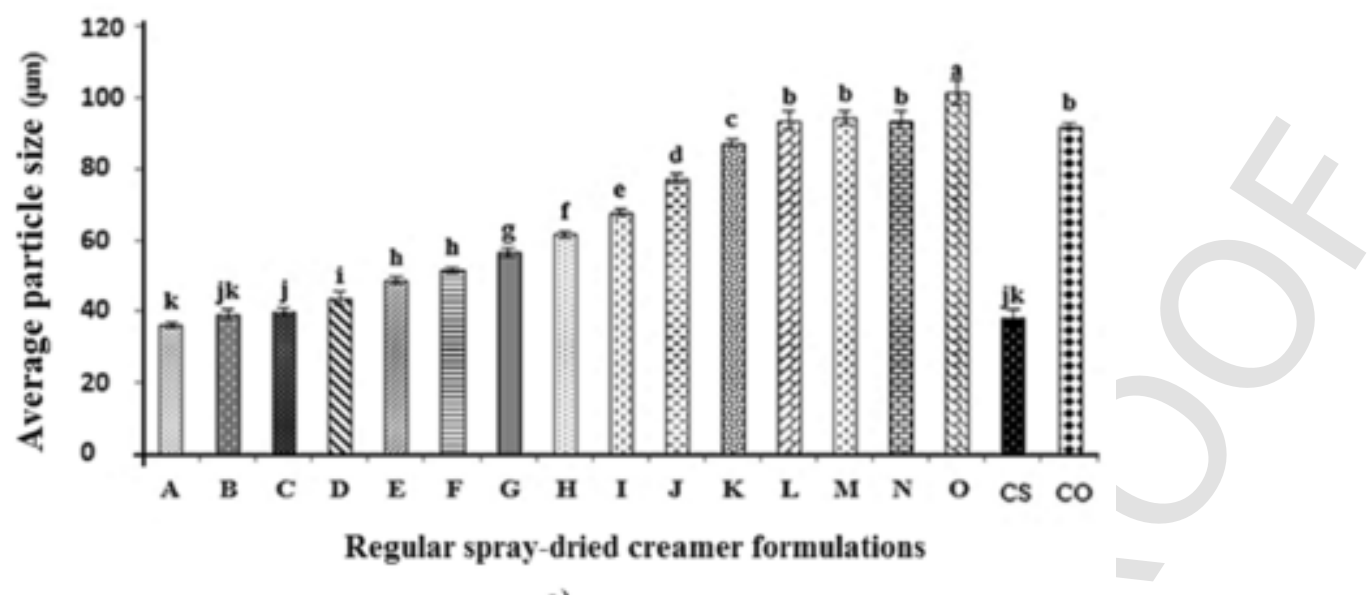

a)

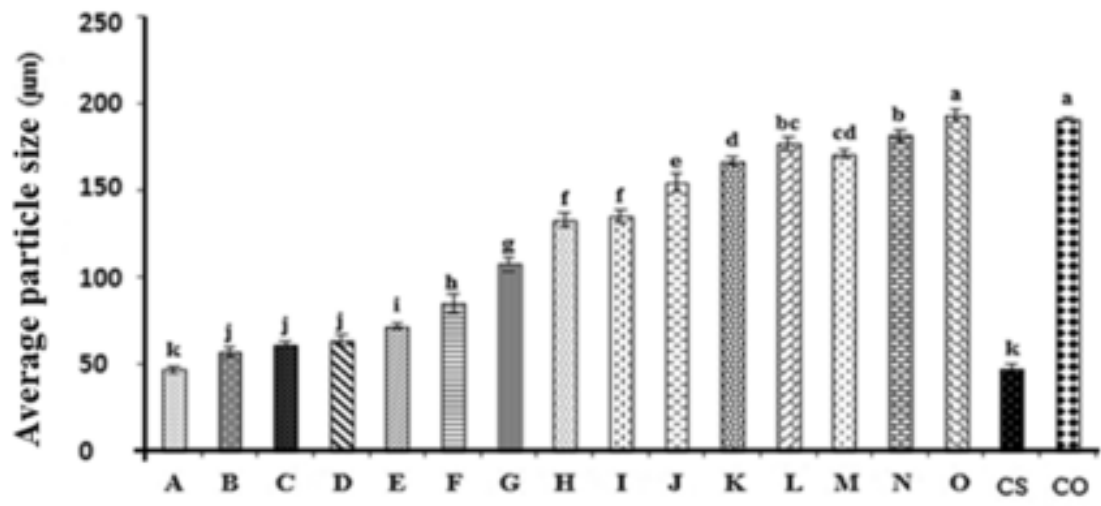

Instant spray-dried creamer formulations

b)

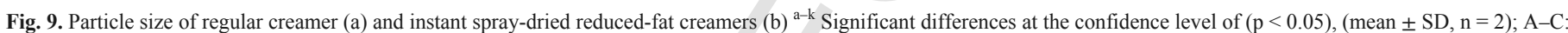

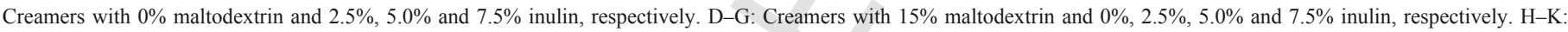

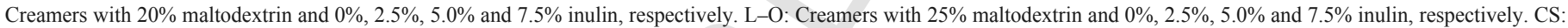
Control sample $(0 \%$ maltodextrin and $0 \%$ inulin; $\mathrm{CO}$ : commercial creamer.

that different instant creamers showed different solubility ranging from $57.72 \%$ to $95.09 \%$ in comparison with the control $(57.81 \%)$ (Fig. 8b). In general, the instant-creamers had higher solubility than the regular-creamers with similar formulations. This might be due to larger particles, higher porosity and lower moisture content of the instant creamers than the regular creamers. As stated by Goula and Adamopoulos (2008), large particles with higher porosity tend to be dissolved easier than the small particles. This is because the small particles have dustier form than large particles and float on water, thus making some difficulties during wetting and reconstitution.

\subsection{Average particle size}

Fig. 5 showed a significantly increase in the particle size of different formulated creamers. The results showed that the creamer $\mathrm{O}$ containing $25 \%$ maltodextrin and $7.5 \%$ inulin exhibited the largest particle size $(101.45 \mu \mathrm{m})$; while the control sample had the smallest particle size among all regular spray-dried dairy creamers, respectively (Fig. 5a). The agglomeration process by fluidized-bed drying technique significantly $(p<0.05)$ increased the volume-weighted mean $\left(\mathrm{D}_{4,3}\right)$ or particle size of the instant spray-creamers compared to the regular creamers (Fig. 5b). The instant spray-dried creamers exhibited different particle size, ranging from 46.45 to $193.26 \mu \mathrm{m}$ com- pared to control creamer $(47.35 \mu \mathrm{m})$ and the commercial instant creamer B $(190.94 \mu \mathrm{m})$ (Fig. 5b). It was found that the agglomeration through fluidized-bed drying also caused stickiness reduction and flowability improvement in the creamer. The application of the spray drying process followed by the agglomeration process resulted in a significant $(\mathrm{p}<0.05)$ better flowability and reconstitution properties than the spray drying alone. Dhanalakshmi et al. (2011) indicated that the powder flowability and reconstitution is highly affected by the particle size, shape and distribution, the particle surface properties as well as the geometry of the system.

\subsection{Sensory attributes}

The most demanding task in developing a reduced fat product is to make a product with the desirable sensory properties. According to http:/ezproxy.upm.edu.my:2055/science/article/pii/ S0023643814002497Tolstoguzov (2003), the properties of a food product mainly reflect the interactions among its components rather than the properties of each component individually. The reduction of fat content in the reduced fat product such as coffee creamer significantly affects its sensory attributes (aroma, taste, texture, appearance and overall acceptability). Therefore, if a hydrocolloid is used as a fat replacer or texture modifier in a food product, its sensory attributes 
should be tested (http://ezproxy.upm.edu.my:2055/science/article/pii/ S0023643814002497Kilcast \& Clegg, 2002).

In the present study, the instant reduced-fat creamer containing $25 \%$ maltodextrin and $7.5 \%$ inulin was selected as the most desirable sample for further sensory analysis. It had the most desirable physicochemical characteristics among all regular-and-instant formulated creamers. Table 5 represents the sensory scores (i.e. taste, aroma, color and overall acceptability) of the most desirable formulated creamer as compared to the commercial creamer. As shown in Table 5, the panels gave almost similar scores to the instant reduced-fat creamer and commercial creamer in terms of taste, aroma and color. This might confirm that the instant reduced fat creamer did not have any significant different taste, aroma, color and overall acceptability in comparison with the commercial creamer. Similar finding was also reported by Arcia, Costell, and Tarrega (2010) for a dairy low-fat dessert fortified with inulin. They reported that dairy low-fat dessert with $5.5 \mathrm{~g} / 100$ inulin did not show any significant different acceptability as compared to the dessert with regular fat. As explained by Karaca, Guven, Yasar, Kaya, and Kahyaoglu (2009), a creamy mouth feel is achieved when inulin is used as a fat replacer in dairy products. They interpreted that this might be due to the interaction of inulin with whey protein and caseinate.

\section{Conclusion}

The current study revealed that the addition of maltodextrin and inulin as a fat replacer in the creamer formulation resulted in the significant reduction of stickiness in the spray-dried creamers. This might be because of the significant improvement of glass transition temperature and thermal behaviour of the reduced-fat creamer. The current study showed that there was a possibility to reduce PKO from $35 \%$ to $8 \%$ with the partial replacement with inulin and maltodextrin (as fat replacer) in the reduced fat coffee creamer. The creamer containing $25 \%$ maltodextrin and $7.5 \%$ inulin had the most desirable quality characteristics among all formulated creamers. The current study proved the synergistic function of inulin and maltodextrin in improving the characteristics of the reduced-fat creamer. This study showed that the instant creamer from two-stage drying process had a higher glass transition temperature $\left(\mathrm{T}_{\mathrm{g}}\right)$, and lower bulk density, moisture content and stickiness than the regular creamer with the same formulation. This might confirm the effectiveness of agglomeration (via fluidized-bed drying) in improving the characteristics of the reduced fat creamer. The current study revealed the successful application of two-stage drying technique (spray drying-fluidizedbed drying) along with partial replacement of fat with inulin and maltodextrin for production of the reduced-fat creamer. According to sensory results, the instant creamer containing $25 \%$ maltodextrin and $7.5 \%$ inulin had comparable sensory properties to the commercial creamer. This study can help the manufactures to produce high-qual-

Table 5

Sensory attributes of the most desirable formulated creamer as compared to the instant commercial creamer.

\begin{tabular}{lll}
\hline Analysis & Tested creamers & \\
& Instant-spray dried creamer & Instant commercial creamer \\
\hline Taste & $7.00 \pm 0.87^{\mathrm{a}}$ & $6.60 \pm 0.96^{\mathrm{a}}$ \\
Aroma & $7.03 \pm 0.99^{\mathrm{a}}$ & $6.60 \pm 1.03^{\mathrm{a}}$ \\
Colour & $6.70 \pm 0.91^{\mathrm{a}}$ & $6.63 \pm 0.92^{\mathrm{a}}$ \\
Overall acceptability & $6.76 \pm 1.04^{\mathrm{a}}$ & $6.46 \pm 0.86^{\mathrm{a}}$ \\
\hline
\end{tabular}

${ }^{a}$ No significant $(\mathrm{p}>0.05)$ difference between samples. ity reduced-fat creamer by using proper fat replacers and two-stage drying (spray drying followed by fluidized bed drying).

\section{Acknowledgements}

We gratefully appreciate the financial support from Ministry of Science, Technology and Innovation for EScience Fund (03-01-04-SF1884).

\section{References}

Aguilar, C.A., Ziegler, G.R., 1994. Physical and microscopic characterization of dry whole milk with altered lactose content. 2. Effect of lactose crystallization. Journal of Dairy Science 77, 1198-1204.

American Dairy Products Institute, 1992. Standards for grades of dry milk including method of analysis, Bull. 916. ADPI, Chicago, IL, USA.

AOAC, 2000. Official methods of analysis, 17th ed. Association of Official Analytical Chemist, Washington, DC.

Arcia, P.L., Costell, E., Tarrega, A., 2010. Thickness suitability of prebiotic dairy desserts: relationship with rheological properties. Journal of Food Research International 43, 2409-2416.

Baruah, B.K., Das, B., Medhi, C., Misra, A.K., 2013. Fertility status of soil in the tea garden belts of golaghat district, Assam, India. Journal of Chemistry 1, 1-6.

Beeson, C. A., \& Erickson, L. (2001). U.S. Patent No. 6,287,616. Washington, DC: U.S. Patent and Trademark Office.

Bhandari, B.R., Howes, T., 1999. Implication of glass transition for the drying and stability of dried foods. Journal of Food Engineering 40, 71-79.

Bhandari, B., Howes, T., 2005. Relating the stickiness property of foods undergoing drying and dried products to their surface energetics. Drying Technology 23, 781-797.

Bröckel, U., Wahl, M., Kirsch, R., Feise, H.J., 2006. Formation and growth of crystal bridges in bulk solids. Chemical Engineering \& Technology 29, 691-695.

Caparino, O.A., Tang, J., Nindo, C.I., Sablani, S.S., Powers, J.R., Fellman, J.K., 2012. Effect of drying methods on the physical properties and microstructures of mango (Philippine 'Carabao' var.) powder. Journal of Food Engineering 111, 135-148.

Chegini, G.R., Ghobadian, B., 2005. Effect of spray-drying conditions on physical properties of orange juice powder. Drying Technology 23, 657-668.

Chiou, D., Langrish, T.A.G., 2007. Crystallization of amorphous components in spraydried powders. Drying Technology 25, 1427-1435.

Chronakis, I.A., 1998. On the molecular characteristics, composition properties, and structural-functional mechanisms of maltodextrins: a review. Critical Reviews in Food Science 38, 599-637.

Cruz, M.A.A., Passos, M.L., Ferreira, W.R., 2005. Final drying of whole milk powder in vibrated-fluidized beds. Drying Technology 23, 2021-2037.

Desai, K.G., Park, H.G., 2004. Solubility studies of valdecoxib in presence of carriers, co-solvent and surfactants. Drug Development Research 62, 41-48.

Dhanalakshmi, K., Ghosal, S., Bhattacharya, S., 2011. Agglomeration of food powder and applications. Critical Reviews in Food Science and Nutrition 51, 432-441.

Drouzas, A.E., Tsami, E., Saravacos, G.D., 1999. Microwave/vacuum drying of model fruit gels. Journal of Food Engineering 39, 117-122.

Elleuch, M., Bedigian, D., Roiseux, O., Besbes, S., Blecker, C., Attia, H., 2011. Dietary fibre and fibre-rich by-products of food processing: characterisation, technological functionality and commercial applications: a review. Food Chemistry $124,411-421$.

Gibson, G.R., Probert, H.M., Van Loo, J., Rastall, R.A., Roberfroid, M.B., 2004. Dietary modulation of the human colonic microbiota: updating the concept of prebiotics. Nutrition Research Reviews 17, 259-275.

Glibowski, P., Bukowska, A., 2011. The effect of pH, temperature and heating time on inulin chemical stability. Acta Scientiarum Polonorum. Seria: Technologia Alimentaria 10, 189-196.

Gong, Z., Zhang, M., Mujumdar, A.S., Sun, J., 2007. Spray drying and agglomeration of instant bayberry powder. Drying Technology 26, 116-121.

Goula, A.M., Adamopoulos, K.G., 2005. Spray drying of tomato pulp in dehumidified air: II. The effect on powder properties. Journal of Food Engineering 66, 35-42.

Goula, A.M., Adamopoulos, K.G., 2008. Effect of maltodextrin addition during spray drying of tomato pulp in dehumidified air: II. Powder properties. Drying Technology 26, 726-737.

Grabowski, J.A., Truong, V.D., Daubert, C.R., 2008. Nutritional and rheological characterization of spray dried sweet potato powder. LWT-Food Science and Technology 41, 206-216.

Hooda, S., Jood, S., 2005. Organoleptic and nutritional evaluation of wheat biscuits supplemented with untreated and treated fenugreek flour. Food Chemistry $90,427-435$.

Johari, G.P., Hallbrucker, A., Mayer, E., 1987. The glass-liquid transition of hyperquenched water. Nature $330,552-553$. 
Kage, H., Nishihara, K., Ishimatsu, H., Ogura, H., Matsuno, Y., 2001. Effect of drying of powder coating efficiency and agglomeration in vibro-fluidized bed. Drying Technology 19, 359-373.

Karaca, O.B., Guven, M., Yasar, K., Kaya, S., Kahyaoglu, T., 2009. The functional, rheological and sensory characteristics of ice cream with various fat replacers. International Journal of Dairy Technology 62, 93-99.

Kelly, P.M., Oldfield, D.J., O'Kennedy, B.T., 1999. The thermostability of spray dried imitation coffee whiteners. International Journal of Dairy Technology $52,107-113$.

Kilcast, D., Clegg, S., 2002. Sensory perception of creaminess and its relationship with food structure. Food Quality and Preference 13, 609-623.

Kim, E.H.J., Chen, X.D., Pearce, D., 2009. Surface composition of industrial spraydried milk powders. 2. Effects of spray drying conditions on the surface composition. Journal of Food Engineering 94, 169-181.

Kumar, P., Mishra, H.N., 2004. Yoghurt powder-a review of process technology, storage and utilization. Food and Bioproducts Processing 82, 133-142.

Maa, Y.F., Nguyen, P.A., Sit, K., Hsu, C.C., 1998. Spray-drying performance of a bench-top spray dryer for protein aerosol powder preparation. Biotechnology and Bioengineering 60, 301-309.

Mishra, P., Srivastava, V., Verma, D., Chauhan, O.P., Rai, G.K., 2009. Physicochemical properties of chakiya variety of amla (Emblica officinalis) and effect of different dehydration methods on quality of powder. African Journal of Food Science 3, 303-306.

Mounir, S., Allaf, K., 2008. Three-stage spray drying: new process involving instant controlled pressure drop. Drying Technology 26, 452-463.

Mukherjee, S., Bhattacharya, S., 2006. Characterization of agglomeration process as a function of moisture content using a model food powder. Journal of Texture Studies $37,35-48$.

Nep, E.I., Conway, B.R., 2011. Physicochemical characterization of grewia polysaccharide gum: effect of drying method. Carbohydrate Polymers 84, 446-453.

Pharmaceutiques, U.D.L., 1995. Dietary modulation of the human colonie microbiota: introducing the concept of prebiotics. Journal of Nutrition 125, 1401-1412.
Ren, G.Y., Li, D., Wang, L.J., Özkan, N., Mao, Z.H., 2010. Morphological properties and thermoanalysis of micronized cassava starch. Carbohydrate Polymers 79, 101-105.

Schuck, P., Jeantet, R., Dolivet, A., 2012. Analytical methods for food and dairy powders. John Wiley \& Sons.

Shrestha, A.K., Howes, T., Adhikari, B.P., Bhandari, B.R., 2007. Water sorption and glass transition properties of spray dried lactose hydrolysed skim milk powder. LWT-Food Science and Technology 40, 1593-1600.

Soukoulis, C., Lebesi, D., Tzia, C., 2009. En rich ment of ice cream with dietary fibre: effects on rheological properties, ice crystallisation and glass transition phenomena. Food Chemistry 115, 665-671.

Sudhagar, M., 2000. Spray drying of fruit juices (Unpublished master dissertation). Department of Agriculture and Food Engineering, Indian Institute of Technology, Kharagpur, India.

Sundaram, J., Durance, T.D., 2008. Water sorption and physical properties of locust bean gum-pectin-starch composite gel dried using different drying methods. Food Hydrocolloids 22, 1352-1361.

Tolstoguzov, V., 2003. Some thermodynamic considerations in food formulation- a review. Food Hydrocolloids 13, 609-623.

Toneli, J., Park, K., Negreiros, A., Murr, F., 2010. Spray-drying process optimization of chicory root inulin. Drying Technology 28, 369-379.

Turchiuli, C., Eloualia, Z., El Mansouri, N., Dumoulin, E., 2005. Fluidised bed agglomeration: agglomerates shape and end-use properties. Powder Technology $157,168-175$.

Uthumporn, U., Zaidul, I.S., Karim, A.A., 2010. Hydrolysis of granular starch at subgelatinization temperature using a mixture of amylolytic enzymes. Food and Bioproducts Processing 88, 47-54.

Word health organization (WHO), 2012. Bulk density and tapped density of powders . Document QAS/11.450. 